\title{
The Application of NMR-Based Metabonomics in Neurological Disorders
}

\author{
Elaine Holmes, ${ }^{*}$ Tsz M. Tsang, ${ }^{*}$ and Sarah J. Tabrizi ${ }^{\dagger}$ \\ *Biological Chemistry, Biomedical Sciences Division, Faculty of Natural Science, Imperial College London, Sir Alexander \\ Fleming Building, South Kensington, London, United Kingdom; and Department of Neurodegenerative Disease, Institute of \\ Neurology, University College London, Queen Square, London, United Kingdom
}

\begin{abstract}
Summary: Advances in postgenomic technologies have radically changed the information output from complex biological systems, generating vast amounts of high complexity data that can be interpreted by means of chemometric and bioinformatic methods to achieve disease diagnosis and prognosis. Highresolution nuclear magnetic resonance (NMR) spectroscopy of biofluids such as plasma, cerebrospinal fluid (CSF), and urine can generate robust, interpretable metabolic fingerprints that contain latent information relating to physiological or pathological status. This technology has been successfully applied to both preclinical and clinical studies of neurodegenerative dis-
\end{abstract}

eases such as Huntington's disease, muscular dystrophy, and cerebellar ataxia. An extension of this technology, ${ }^{1} \mathrm{H}$ magicangle-spinning (HRMAS) NMR spectroscopy, can be used to generate metabolic information on small intact tissue samples, providing a metabolic link between metabolic profiling of biofluids and histology. In this review we provide a summary of high-resolution NMR studies in neurodegenerative disease and explore the potential of metabonomics in evaluating disease progression with respect to therapeutic intervention. Key Words: Metabonomics, NMR spectroscopy, neurodegeneration, chemometric, biomarker.

\section{INTRODUCTION}

As we progress toward a systems approach to understanding disease etiology and evolution via the use of postgenomic disciplines such as transcriptomics, proteomics, and metabonomics, the conceptual framework for analysis and data interpretation has shifted. Traditionally, strategies have been employed whereby a few response vectors have been measured in sequence on the basis of a predetermined hypothesis. The framework adopted favored a single stimulus-single response structure, such as protein phosphorylation and therefore was designed to model simple linear pathways. However, there is increasing recognition of biological complexity and the need to integrate technologies and their outputs into a systems-based approach. Therefore, the conceptual paradigm has been shifted to accommodate the complexity of biological networks ${ }^{2,3}$ (as described by Miller and Federoff ${ }^{4}$ and Olson ${ }^{5}$ in the current issue).

Address correspondence and reprint requests to: Elaine Holmes, Ph.D., Biological Chemistry, Biomedical Sciences Division, Faculty of Natural Science, Imperial College London, Sir Alexander Fleming Building, South Kensington, London, SW7, 2AZ, UK. E-mail: elaine.holmes@imperial.ac.uk
As with all "omics" methodologies, metabonomic technology is approaching a deeper level of maturity and is beginning to fulfill its potential in the diagnostic characterization of disease with promise of prognostic capabilities in some disease areas. Moreover, it has a key role in the discovery and development of new treatments for human disease. Metabonomics, which is defined as "the quantitative measurement of the dynamic multiparametric metabolic response of living systems to pathophysiological stimuli or genetic modification," involves the determination of comprehensive metabolite profiles of biological matrices (biofluids, cells, tissues). Metabonomic technology largely relies on advanced spectroscopic platforms such as nuclear magnetic resonance (NMR) spectroscopy and mass spectrometry (MS) that generate high-density data from biological samples providing a characteristic "fingerprint pattern" for a range of biologically important endogenous metabolites ${ }^{6,7}$ that reflect the physiological or pathological status of an organism. Latent information pertaining to the "global" metabolic status of an individual and encoding metabolic responses to genetic and environmental factors, such as nutrition, aging, gender, stress, and disease, can be extracted from the spectral data using multivariate mathe- 
matical modeling tools ${ }^{6,8}$ (see Olson ${ }^{5}$ in the current issue for further explanation). A wide range of bioinformatic and chemometric modeling strategies can be applied to define the metabolic boundaries of disease and to monitor progression of disease with and without therapeutic intervention. Several such examples exist in the literature based on NMR spectroscopy, HPLC-MS, GC-MS, and also MS-based methods with electrochemical detection, spanning a range of diseases including cancer, ${ }^{9-11}$ diabetes ${ }^{12}$ coronary heart disease, ${ }^{13,14}$ neurological disease, ${ }^{15-17}$ metabolic disorders ${ }^{18}$ and infectious diseases. ${ }^{19-21}$

In the current review we focus on the development and application of NMR-based metabonomic technology in the field of neurological disease and explores its potential in evaluating therapeutic strategies.

\section{HISTORY OF NMR TECHNOLOGY IN STUDYING NEUROLOGICAL DISORDERS}

The history of magnetism in medicine dates back to the legendary discovery by the shepherd Magnes around $1000 \mathrm{BC}$ of a magnetic substance later known as lodestones ("lead" stones) or "stones that point the way."22 In the 15th century, a Swiss physician named Paracelsus used lodestones to filter diseases such as epilepsy, diarrhea, and hemorrhage from the body. He believed that the ability of magnets to attract iron could be replicated by attracting disease away from the body. In the late 18th century, the Austrian physician Franz Anton Mesmer, who popularized the use of hypnotism in medicine in France, described the healing properties of passing magnets over the open veins of patients. A Board of Inquiry containing prominent scientists was established by King Louis XVI to validate the effects of "animal magnetism" or "mesmerism." In what is considered to be perhaps the first placebo-controlled trial of a therapy ever conducted, Benjamin Franklin constructed an experiment in which a blindfolded patient was shown to respond as much to a nonprepared tree as to one that had been "magnetized." In the mid-19th century, magnetic ointments produced in New York were introduced as remedies for a whole spectrum of illnesses such as headaches, inflammation of the bowels, burns, fever sores, rheumatism, gout, and toothache.

In 1952 the Nobel Prize in physics was awarded to Edward Purcell and Felix Bloch for their discovery of nuclear magnetic resonance in 1945, and since then a further seven Nobel Prizes have been issued to pioneers in applications of NMR in chemistry, biochemistry, and medicine. Magnetic resonance works on the principle that the electrons and the nucleus of many isotopes possess a property called spin, which causes these charged particles to behave like small bar magnets when placed in a magnetic field, aligning themselves with or against the magnetic field. When energy is introduced into the system in the form of radiofrequency, the particles absorb energy and are said to be on resonance. Since the different atoms of a given nuclei within a molecule, such as ${ }^{1} \mathrm{H}$, resonate at slightly different frequencies, dependent upon their electronic environment, information about the chemical structure of a molecule can be obtained.

Nuclear magnetic resonance technology has been used extensively in the field of neurodegeneration, both as an imaging tool to generate anatomical information via the measurement of water molecules in different physical environments and as magnetic resonance spectroscopy (MRS), which provides chemical structural information from in vivo tissues. Magnetic resonance imaging (MRI) has been established as one of the most important clinical diagnostic tools for diseases such as multiple sclerosis, ${ }^{23-25}$ and Alzheimer's disease (AD) ${ }^{26}$ Magnetic resonance imaging has also been used to characterize neural changes in diseases such as Creutzfeldt-Jakob syndrome, ${ }^{27}$ Huntington's disease (HD) ${ }^{28}$ HallervordenSpatz disease, ${ }^{29}$ Alexander's disease, ${ }^{30}$ Cushing's syndrome, ${ }^{31,32}$ and bipolar disorder. ${ }^{33}$ Although MRI is an extremely important clinical tool, MRS and high-resolution NMR spectroscopy of biofluids and tissues are more useful in the context of systems biology since they generate multivariate information on a wide range of molecules.

${ }^{1} \mathrm{H}$ MRS has sufficient sensitivity to detect a range of neurochemicals including amino acids (alanine, aspartate, glutamate, glutamine, taurine), organic acids $(\gamma$ aminobutyric acid, lactate), phosphocreatine, phosphoethanolamine, phosphocholine, glycerophosphocholine, inositols (myo-inositol, scyllo-inositol) and its use in neurological studies has been reported in a number of reviews. ${ }^{22,34}$ Other nuclei that are of use include ${ }^{13} \mathrm{C}$ and ${ }^{31} \mathrm{P}$, although the sensitivity of these nuclei preclude them from being used routinely in MRS studies. Since lesions in the brain are generally localized, MRS is performed on small tissue volumes or voxels, typically $1-2$ $\mathrm{cm}^{3}$. Absolute quantitation of metabolites from in vivo tissues is problematic since it is not possible to use an internal reference standard, and therefore metabolite concentrations are usually expressed as a ratio to a metabolite that does not change with disease or intervention. Many neurological conditions that have been successfully characterized by MRS include epilepsy, ${ }^{35}$ amyotrophic lateral sclerosis (ALS), ${ }^{36,37}$ Parkinson's disease (PD) ${ }^{38,39} \mathrm{HD},{ }^{28,39}$ and $\mathrm{AD},{ }^{40,41}$ to name but a few. MRS has also been used to increase the specificity of noninvasive diagnosis of brain tumors. ${ }^{42}$ Although alanine may be present in several types of tumor, it is only clearly distinguishable from lactate in meningiomas. An overview of the use of MRS in the study of transgenic models of PD, AD, HD, and ALS is given by Choi et al. ${ }^{34}$ 
High-resolution NMR spectroscopy can be used to analyze ex vivo tissues and biofluids such as CSF, blood plasma, and urine and provides a uniquely powerful means of investigating the metabolic composition of such samples, since the rich atom-centered information generated often allows direct structural elucidation of metabolites. Unlike MRS, high-resolution NMR spectroscopy is not compromised by poor spectral resolution and can routinely access metabolites present at micromolar concentrations. For example, whereas alterations in relative concentrations of lipoprotein fractions may contribute to characterization and diagnosis of disease tissues, MRS commonly "edits out" the contributions of these signals. The use of more specialized NMR probes, such as cryoprobes and microprobes, offers further enhancement in sensitivity, lowering the detection limit to the nanogram range. Historically, high-resolution NMR spectroscopy originated in the elucidation of chemical structures. In 1977, Brown and coworkers ${ }^{43}$ applied ${ }^{1} \mathrm{H}$ NMR spectroscopy to the study of red cell metabolism and in 1979 the technology was applied to blood serum and identified elevated lactate in patients with malignant tumors. ${ }^{44}$ In the 1980s, Nicholson and coworkers ${ }^{45-47}$ adapted the technology for routine measurement of biofluids and over the next decade high-resolution NMR spectroscopy was used progressively, mainly for drug metabolism and toxicology studies in experimental animals. A number of human clinical studies were also undertaken in the 1980s and early $1990 \mathrm{~s},{ }^{45}$ but such studies were restricted to overt disease, since the capacity for sample acquisition was limited and spectral interpretation was performed manually. Nuclear magnetic resonance spectroscopic analysis has now been used to investigate the mammalian brain and has been particularly useful as a diagnostic tool. ${ }^{48-51}$ For example, Cheng and coworkers ${ }^{49}$ were able to distinguish between normal tissues and a number of brain tumor types, reporting correlations in metabolite ratios with tumor grade. In recent years, NMR technology has undergone revolutionary improvements in terms of capacity for sample throughput, increased sensitivity, physical hyphenation with other analytical spectroscopic tools, and improved processing and modeling software. The analytical features that have maximized the performance of NMR spectroscopy in clinical studies are summarized below.

\section{KEY ANALYTICAL DEVELOPMENTS IN NMR SPECTROSCOPY}

Recent advances in both NMR spectrometer hardware and the mathematical tools available for spectral interpretation have revolutionized the field, conferring a huge increase in analytical sensitivity. A sample throughput of 200-300 samples/day/spectrometer can be achieved via the use of flow-injection NMR under optimized condi- tions. Typically, high-throughput screening and evaluation of drug toxicity and metabolism analyses are conducted on $600 \mathrm{MHz}$ NMR spectrometers since this gives an adequate performance with a good cost:benefit ratio and much of the research to date has been conducted at $600 \mathrm{MHz}$. However, the increase in sensitivity and dispersion achieved at higher fields such as $800-900 \mathrm{MHz}$ is sometimes necessary for metabolite identification. ${ }^{52,53}$ One of the major limiting technical factors in NMR spectroscopy, in general, is its rather low inherent sensitivity compared with other types of analytical detection methods. A critical development in overcoming this limitation has been the recent commercialization of NMR detectors (probes) cooled to near cryogenic temperatures, usually around $20 \mathrm{~K}$, which improve the signal-to-noise ratio (SNR) via reduction of the thermal (Johnson) noise level by a factor proportional to the square root of the temperature ratio. ${ }^{54}$ In practice, this results in an improvement of around $400 \%$ in sensitivity (for a single scan) and reduces the data acquisition time by $\sim 16$ fold. With the gain in SNR, the use of other less sensitive nuclei in biofluid analysis such as ${ }^{13} \mathrm{C},{ }^{15} \mathrm{~N}$, or ${ }^{31} \mathrm{P}$ becomes possible. ${ }^{55,56}$ In addition, the improved SNR of cryoprobes allows the acquisition of two-dimensional (2D) NMR data; i.e., the use of a second frequency domain to improve the dispersion of the spectra and to generate structural information on correlation between neighboring nuclei in a time frame suitable for metabonomic screening.

Since biological samples are chemically complex, often containing hundreds or thousands of metabolites, one-dimensional (1D) spectroscopy produces crowded spectra in which low concentration metabolites may be obscured. For example, biofluids such as serum, bile, or intact tissues, which contain a mixture of macromolecular (e.g., lipoproteins, cholesterol) and low molecular weight components (e.g., amino acids, carboxylic acids), can be difficult to interpret using standard 1D sequences, since the sharper resonances arising from low molecular weight species are superimposed with the broader macromolecular resonances. In this case, it is often appropriate to use more than one pulse sequence, for instance a spin-echo sequence, to enhance the contribution of the low molecular weight metabolites or diffusion edited sequences to edit out the low molecular weight components and focus on the lipoprotein and higher molecular profile. ${ }^{57,58}$ Methods for reducing overlapped metabolite resonances and increasing the molecular structural information include dispersion of the spectral data using a second dimension, for which a range of $2 \mathrm{D}$ pulse sequences exist. ${ }^{59,60}$ Once a potential biomarker candidate of disease class or response has been identified, then the NMR spectroscopic detection can be physically integrated with HPLC-MS to effect simultaneous molecular characterization of separated biomolecules from biofluid 
samples. ${ }^{61}$ The recent development of ultra high-pressure liquid chromatography (UPLC) has further enhanced the capabilities for metabolite isolation and detection. The advances offered by UPLC include higher metabolite concentration per band, more rapid separation, and improved resolution. UPLC-MS can be used in its own right to generate information-rich metabolite profiles for disease diagnosis. ${ }^{62}$ Coupled with the increase in sensitivity offered by the cryo-flow probes, UPLC offers the possibility of a dramatic improvement in the ability to perform high-throughput metabolic analysis and substantially improves the limits of biomarker detection.

In the past decade it has become possible to analyze intact tissues using a technique called magic-anglespinning (MAS) NMR spectroscopy based on technology adapted from solid-state studies. This technique has been applied to the study of organ-specific toxicity, ${ }^{63}$ characterization of tissue composition and structure, ${ }^{64}$ the analysis of needle biopsies of human samples ${ }^{65}$ cell systems, ${ }^{55}$ tumors,,${ }^{51,66}$ and to study dynamic information in tissue compartments. ${ }^{19}$ Since only $\sim 10 \mathrm{mg}$ of tissue is needed, this approach is directly applicable to clinical biopsy samples. Like MRS, the exact quantitation of metabolite changes is difficult, as it is not possible to add an external quantitation standard. Therefore, metabolite changes are usually expressed as ratios to a selected metabolite or relative to the sum of the spectrum, adjusted for tissue weight. However, MAS provides a direct metabolic link between biofluid profiles and histopathology and can also be used to observe compartmentalization of metabolites and dynamic tissue changes in real time. ${ }^{19}$

\section{DEVELOPMENTS IN MATHEMATICAL PROCESSING AND MODELING TOOLS}

Since analytical spectra are highly complex objects and the dynamic range of signal intensities results in a visual bias toward high-intensity signals, computerbased Pattern Recognition (PR) algorithms were developed for data reduction and spectral interpretation. Initially multivariate statistical methods were applied to the analysis of NMR biofluid data to classify ${ }^{1} \mathrm{H}$ NMR spectra according to their origin (e.g., healthy or diseased, control, or toxin treated) based on a number of scored or quantified metabolites. There are many different mathematical algorithms for establishing similarities between samples and for extracting variables or features that are important in discriminating between two or more groups of samples. These methods have derived from many academic fields including artificial intelligence, chemistry, economics, psychology, and biology and include linear projection methods [e.g., principal components analysis (PCA), projection to latent structure regression], clustering analyses, Bayesian probabilistic approaches, genetic algorithms, and artificial neural networks. ${ }^{67-70}$ Each of these methods has associated strengths and weaknesses. We illustrate the principle of PR here using basic PCA.

Principal component analysis reduces the initial variables (NMR descriptors) to a smaller set of variables termed principal components (PCs) by means of a linear transformation, which allows the main variation in the dataset to be visualized while reducing irrelevant noise. Principal components are new variables that are orthogonal to each other and explain progressively less variance in the data set. They can be displayed in two- or three-dimensional "scores plots," allowing visualization of the distribution and grouping of the samples in the new variable space. Since each PC is a combination of the original input variables, each original variable (or NMR signal) is given a weight (loading) that indicates the strength of influence that variable has on the overall distribution of samples. These weights can be displayed as loadings plots that indicate which spectral regions are dominating the differentiation between groups of samples (FIG. 1).

Chemometric modeling of spectroscopic data has, to a large extent, developed to accommodate the increased sensitivity and sample throughput of NMR technology. Sophisticated algorithms have been developed for metabonomic analysis that can use the full spectral resolution (typically $64 \mathrm{~K}$ data points) and better accommodate the biological complexity in mammalian systems. While algorithms such as PCA have been used with considerable success in metabonomic analysis for data reduction and to allow the visualization of inherent structure in the data, spectral data from human urine or serum contains latent information on a range of diverse genetic and environmental influences, which inhibit derivation of the effects of single factors or stimuli. Data-filtering strategies and other preprocessing methods can be used to optimize models and to increase the interpretability of the models. Incorporating an orthogonal filtration step into methods such as projection to latent structure discriminant analysis (O-PLS-DA) can achieve separation of the systematic variation of interest from the systematic variation deriving from confounding sources, such as inherent physiological variation, but still retain the ability to interpret both types of variation independently to gain a better understanding of the variation in the data. ${ }^{68,71}$ Statistical algorithms can also be applied directly to the identification of biomarkers in NMR spectra. Since each proton environment within a metabolite generates a separate signal of the NMR chemical shift scale, the calculation of a correlation matrix for a set of samples driven from the apex of a selected resonance will highlight correlated signals deriving from the same molecule and down weight other metabolite contributions to the spectra not correlated to the molecule of interest. Many 

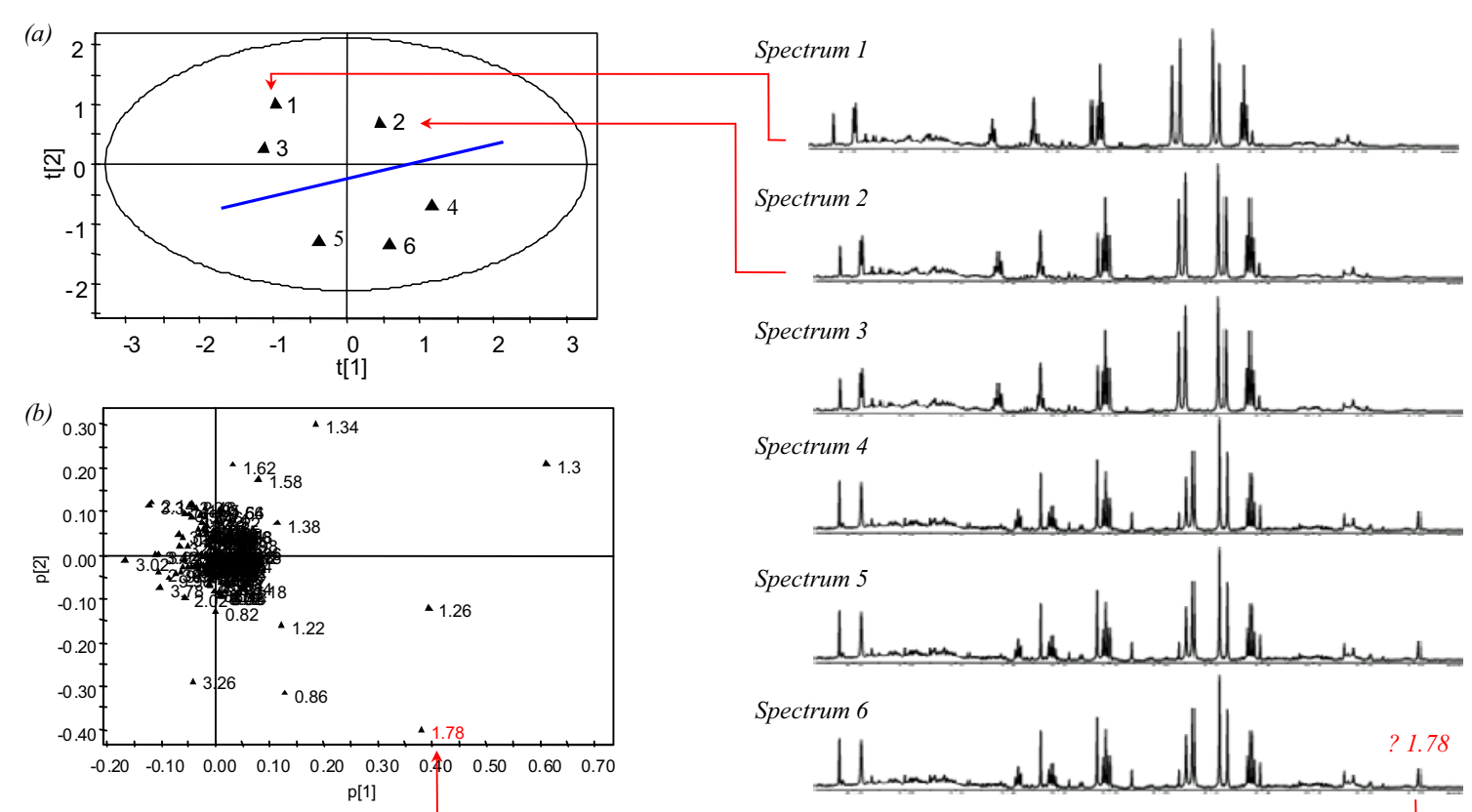

Spectrum 5

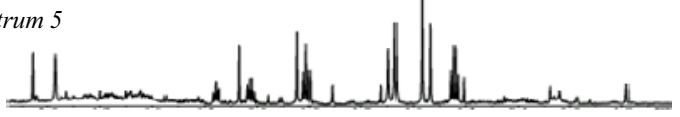

Spectrum 6

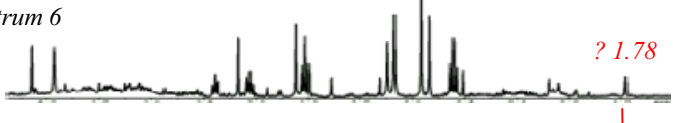

FIG. 1. An illustration of how ${ }^{1} \mathrm{H}$ NMR spectra (spectra 1-6) can be reduced and visualized in a 2D PCA scores plot. (a) Each spectrum can be viewed as an observation in PCA space (as exemplified by arrows for spectra 1 and 2) where the proximity of observations represents the similarity of the metabolic profiles of the biological samples. (b) The corresponding loadings plot presents the variables attributable to the spatial localization of the spectrum in the scores plot. In this example, spectra 1-3 are metabolically distinct from spectra 4-6 in the scores plot. Several variables contribute to the separation of clusters including variable $\delta 1.78$. Cross-referencing back to the spectra reveals the presence of an additional peak that is only exhibited in spectra 4-6.

of the statistical methods developed for modeling NMR data can be applied equally successfully to modeling gene expression or proteomic data. ${ }^{67}$ There is currently a drive toward integration of "omics" data sets with subsequent mapping of significant variables (genes, proteins, metabolites) onto biological pathways and networks to achieve a more holistic picture of the dynamic and interactive biological processes occurring in an organism (as demonstrated by Ma'ayan and coworkers ${ }^{72}$ in the current issue).

\section{APPLICATIONS OF HIGH-RESOLUTION NMR SPECTROSCOPY IN NEUROLOGICAL DISORDERS}

The neurochemical profile of the mammalian brain has been well characterized by both MRS and high-field ${ }^{1} \mathrm{H}$ NMR spectroscopy. ${ }^{73-75,148}$ Differences in structure and function between various distinct neuroanatomical regions have also been elucidated using both MAS of intact tissues and tissue extracts, ${ }^{75}$ with the sensitivity and specificity of the analysis allowing differentiation between closely related structures such as the dorsal and ventral striatum. ${ }^{75,76}$ As many neurodegenerative disorders exhibit neuronal loss in selective anatomical regions, e.g., caudate and putamen in HD and substantia nigra pars compacta in PD, NMR spectroscopic analysis requires the examination of specific localized regions. In addition, the effect of development and maturation on brain structure has also been explored (FIG. 2). Metabolic profiles for neural cell lines (e.g., neuronal and glial) have also been established using high-resolution NMR spectroscopy. ${ }^{77,78}$ Such information may allow the interpretation of metabolic perturbations observed by ${ }^{1} \mathrm{H}$ NMR spectroscopy, for example, in cases in which selective neuronal loss or abnormal development is expected or in patients with brain tumors in which changes in cell populations may occur. Although many changes observed in neurological disorders are associated with specific neuroanatomical regions and are disease specific, certain metabolic changes are globally indicative of degeneration. The most common of these changes is a decrease in $N$-acetylaspartate (NAA) in brain tissues, which is indicative of neural loss and has been reported following $\mathrm{AD},{ }^{41,48} \mathrm{HD},{ }^{79-81}$ Rett's syndrome, ${ }^{82} \mathrm{PD},{ }^{39,83}$ ALS, ${ }^{36,37}$ multiple sclerosis, ${ }^{23,84}$ Batten's disease, ${ }^{85}$ and traumatic brain injury. ${ }^{86}$ A summary of the key NMR spectroscopic-based studies in neurodegenerative disease and models of neurological disorders are listed in Table 1.

\section{Preclinical metabonomic studies}

Toxicological models of neurodegenerative disease. Toxicological studies into various neuroactive compounds have provided invaluable insight into the etiology of a number of neurodegenerative disorders. The 

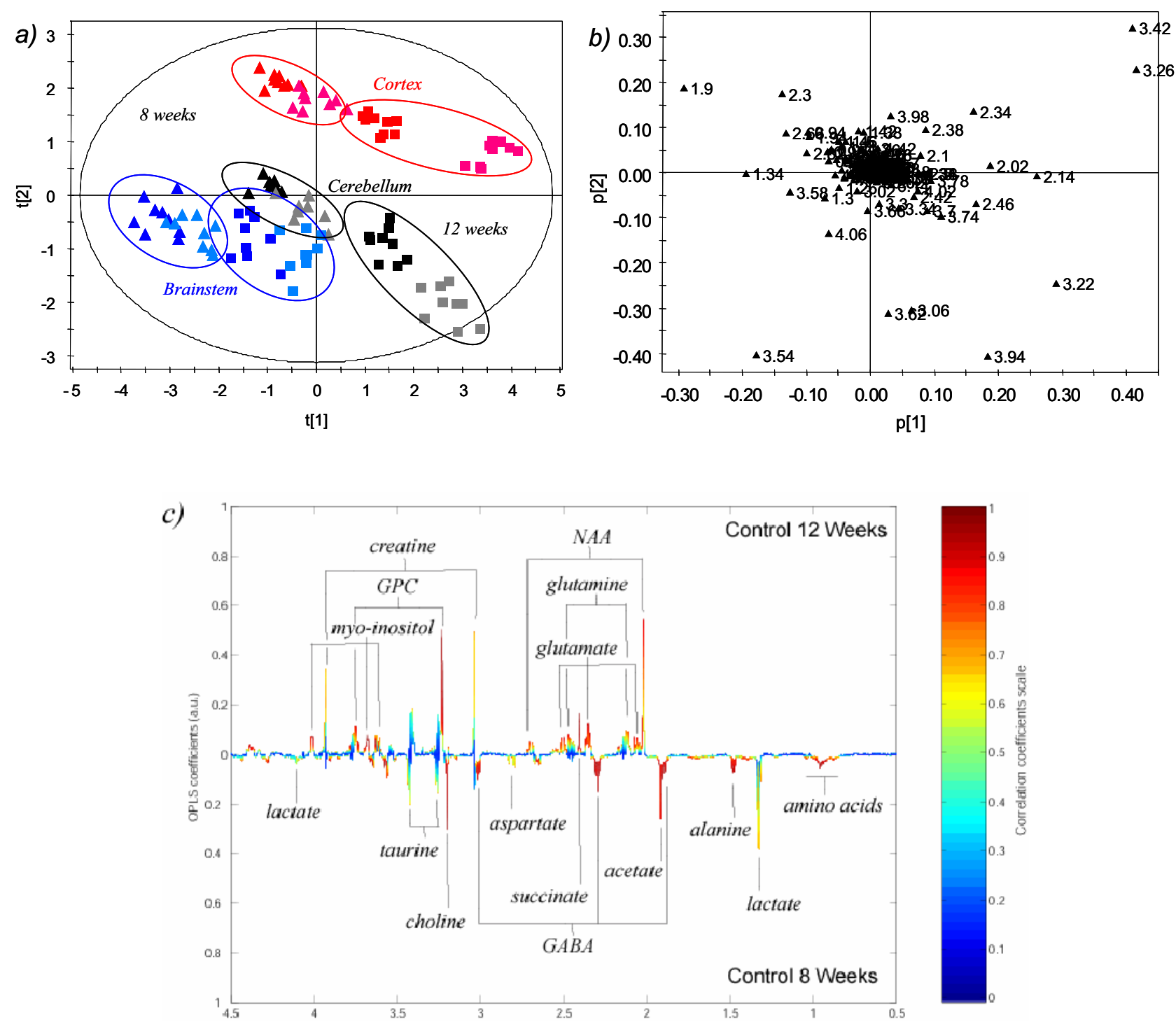

FIG. 2. (a) A PCA scores plot mapping ${ }^{1} \mathrm{H}$ NMR spectra of aqueous extracts of cerebellum, cortex, and brainstem samples from R6/2 transgenic and control mice. Visualization of the metabolite profiles from R6/2 transgenic and wild-type mice in PCA reveals a clear distinction at 8 and 12 weeks. (b) The corresponding loadings plot presents the variables attributable to the class separation. (red $=$ frontal cortex extracts from wild-type mice; pink = frontal cortex extracts from R6/2 mice; black = cerebellum extracts from wild-type mice; gray = cerebellum extracts from R6/2 mice; dark blue = brainstem extracts from wild-type mice; light blue = brainstem extracts from R6/2 mice; $\boldsymbol{\Delta}=8$-week-old; $\boldsymbol{\square}=12$-week-old); (c) A coefficient plot showing the metabolic differences associated with maturation (8-12 weeks) in wild-type mice.

administration of neurotoxins to experimental animals has produced many models with clinical phenotypes analogous to human disorders. Some toxins share the ability to selectively destroy specific neuroanatomical regions that are primarily associated with specific diseases.

Parkinson's disease. Both genetic and environmental factors have been implicated in the onset and development of PD. Twin studies, ${ }^{87,88}$ case control studies, ${ }^{89,90}$ and the identification of mutations in several genes in familial $\mathrm{PD}^{91-97}$ point to there being a significant genetic contribution to the etiology of $\mathrm{PD}$, in at least a proportion of patients. The association of environmental toxins with parkinsonism derives from studies implicating carbon monoxide,${ }^{98}$ manganese,${ }^{99}$ industrial herbicides, ${ }^{100}$ and, most importantly, 1-methyl-4-phenyl-1,2,3,6 tetrahydropyridine (MPTP). ${ }^{101}$ In reality, it would appear that PD is a heterogeneous disease likely to be caused by more than one specific etiological factor. This is supported by the fact that the clinical and pathological syndromes associated with environmental agents are remarkably similar to those observed with familial PD cases.

Over the years, investigators have developed the use of agents that selectively disrupt or destroy catecholaminergic systems to produce animal models of PD. Several compounds such as reserpine, ${ }^{102}$ 6-hydroxy- 
TABLE 1. Summary of Some Key NMR Spectroscopy-Based Studies in Neurodegenerative Conditions

\begin{tabular}{|c|c|c|}
\hline Neurological Disease & Study & Reference \\
\hline & $\begin{array}{l}\text { Identification and characterization } \\
\text { of mammalian brain metabolites }\end{array}$ & $\begin{array}{l}\text { Tsang et al., }{ }^{75} \text { Tkac et al., }{ }^{148} \text { Pfeuffer et al., }{ }^{74} \text { Govindaraju et } \\
\text { al. }\end{array}$ \\
\hline $\begin{array}{l}\text { Spinocerebellar } \\
\text { ataxia }\end{array}$ & $\begin{array}{l}\text { Metabolic characterization of the } \\
\text { SCA3 (Machado-Joseph } \\
\text { disease) mouse model }\end{array}$ & Griffin et al. ${ }^{1,15}$ \\
\hline \multirow[t]{3}{*}{ Parkinson's disease } & $\begin{array}{l}\text { Analysis of brain metabolite } \\
\text { perturbations in toxin-induced } \\
\text { primate model for PD }\end{array}$ & Brownell et al. ${ }^{109}$ \\
\hline & $\begin{array}{l}\text { Characterization of metabolite } \\
\text { perturbations in PD and } \\
\text { neurodegenerative parkinsonism }\end{array}$ & Hoang et al., ${ }^{79}$ Luccetti et al., ${ }^{83}$ Seppi and Schocke ${ }^{38}$ \\
\hline & $\begin{array}{l}\text { Metabolite analysis after } \\
\text { thalamotomy as putative } \\
\text { therapy for PD }\end{array}$ & Baik et al. ${ }^{140,141}$ \\
\hline \multirow[t]{6}{*}{ Huntington's disease } & $\begin{array}{l}\text { Characterization of the metabolite } \\
\text { perturbations and impaired } \\
\text { energy metabolism in PD }\end{array}$ & Hoang et al., ${ }^{79}$ Jenkins et al. ${ }^{28,81}$ \\
\hline & $\begin{array}{l}\text { Metabolic characterization of } \\
\text { toxin-induced and transgenic } \\
\text { animal models of HD }\end{array}$ & $\begin{array}{l}\text { Tsang et al., }{ }^{76} \text { Jenkins et al., }{ }^{121} \text { van Dellen et al., }{ }^{120} \text { Dautry et } \\
\text { al. }{ }^{113,149}\end{array}$ \\
\hline & $\begin{array}{l}\text { Evaluation of creatine } \\
\text { supplementation in HD models } \\
\text { and patients }\end{array}$ & $\begin{array}{l}\text { Bender et al., }{ }^{90} \text { Verbessem et al., }{ }^{142} \text { Matthews et al., }{ }^{150} \text { Tabrizi } \\
\text { et al., }{ }^{146} \text { Kasparova et al. }{ }^{39}\end{array}$ \\
\hline & $\begin{array}{l}\text { Evaluation of striatal allografts in } \\
\text { primate model of HD }\end{array}$ & Palfi et al. ${ }^{114}$ \\
\hline & $\begin{array}{l}\text { Evaluation of ciliary neurotrophic } \\
\text { factor in primate model of HD }\end{array}$ & Mittoux et al. ${ }^{115}$ \\
\hline & $\begin{array}{l}\text { Metabolic profiling of blood sera } \\
\text { from HD patients }\end{array}$ & Underwood et al. ${ }^{122}$ \\
\hline Alzheimer's disease & $\begin{array}{l}\text { Metabolic characterization to } \\
\text { improve the understanding and } \\
\text { diagnosis of } \mathrm{AD}\end{array}$ & $\begin{array}{l}\text { Fernandez et al., }{ }^{40} \text { Pfefferbaum et al., }{ }^{41} \text { Cheng et al., }{ }^{48} \\
\text { Frederick et al. }\end{array}$ \\
\hline Schizophrenia & $\begin{array}{l}\text { Metabolic characterization of } \\
\text { human brain tissues from } \\
\text { schizophrenic patients }\end{array}$ & Prabakaran et al. ${ }^{17}$ \\
\hline Bipolar disorder & Biomarker evaluation & Gallelli et al. ${ }^{33}$ \\
\hline $\begin{array}{l}\text { Meningitis and } \\
\text { ventriculitis }\end{array}$ & $\begin{array}{l}\text { Evaluation of metabonomics as a } \\
\text { diagnostic tool }\end{array}$ & Coen et al. ${ }^{19}$ \\
\hline Multiple sclerosis & $\begin{array}{l}\text { Characterization of the metabolic } \\
\text { consequences during relapsing- } \\
\text { remitting episodes of MS }\end{array}$ & $\begin{array}{l}\text { Kapeller et al., }{ }^{23} \text { Karrenbauer et al., }{ }^{24} \text { Tartaglia and Arnold, }{ }^{25} \\
\text { Matthews et al., }{ }^{37} \text { Tourbah et al., }{ }^{34} \text { Mader et al., }{ }^{130} \text { Arnold et } \\
\text { al. }{ }^{131,135}\end{array}$ \\
\hline Cushing's syndrome & $\begin{array}{l}\text { Brain metabolite alterations in } \\
\text { Cushing's syndrome }\end{array}$ & Khiat et al. ${ }^{31,32}$ \\
\hline $\begin{array}{l}\text { Amyotrophic lateral } \\
\text { sclerosis }\end{array}$ & $\begin{array}{l}\text { Screening the efficacy of potential } \\
\text { therapeutic agents for ALS }\end{array}$ & Kalra $^{36}$ \\
\hline Human brain tumors & $\begin{array}{l}\text { Characterize and differentiate } \\
\text { types of brain tumors }\end{array}$ & Preul et al., ${ }^{42}$ Cheng et al., ${ }^{49}$ Barton et al. ${ }^{51}$ \\
\hline Rett syndrome & $\begin{array}{l}\text { Characterization of the metabolic } \\
\text { changes occurring in Rett } \\
\text { syndrome }\end{array}$ & Horska et al. $^{82}$ \\
\hline Batten disease & $\begin{array}{l}\text { Phenotypic characterization of a } \\
\text { mouse model for Batten disease }\end{array}$ & Pears et al. ${ }^{85}$ \\
\hline
\end{tabular}

dopamine (6-OHDA), ${ }^{103}$ and MPTP ${ }^{101}$ cause the specific degeneration of the nigrostriatal cells, providing good pharmacological models of PD. Direct injection of 6-OHDA into the substantia nigra produced the first toxin model of PD. ${ }^{103}$ The selective accumulation of this toxin in dopaminergic neurons leads to their death, pre- sumably mediated by oxidative stress. ${ }^{104}$ Animals have a quantifiable motor deficit, but the characteristic Lewy bodies observed in human patients are not seen, and there is nonspecific toxin-induced damage to neighboring neurons. This model has been particularly useful for pharmacological screening but does not replicate many key 
clinical features of PD. Parkinsonism in drug addicts caused by drugs contaminated with MPTP, ${ }^{101}$ an inhibitor of complex I of the mitochondrial respiratory chain, led to the development of mouse and primate models of PD using this neurotoxin. ${ }^{105}$ In nonhuman primates, MPTP causes tremor, rigidity, akinesia, and postural instability, which are all successfully treated with L-Dopa and dopamine agonists. Dopaminergic neurons are selectively lost in brain areas similar to idiopathic PD, including the substantia nigra. However, MPTP-induced subacute or acute onset parkinsonism lacks the typical electron microscopy features of Lewy bodies. ${ }^{101}$ It is unknown whether chronic administration of MPTP may induce the formation of Lewy bodies. The MPTP model represents the best characterized model of PD and fulfills many of the criteria for the ideal model of the disease with the exception of Lewy body formation. It is the study of MPTP-lesioned animals that has led to most of the current surgical and pharmacological therapies for PD.

Relatively little analysis has been carried out on the metabolic profiling of toxin-induced PD models given the wealth of information from imaging studies performed. ${ }^{106-108}$ However, metabonomic strategies have been applied in a primate model of PD. ${ }^{109}$ Chronic low doses of MPTP were infused to selectively target subpopulations of dopaminergic neurons and present a stable Parkinsonian syndrome, increases in striatal choline and lactate together with decreases in NAA were described, which persisted months after the termination of toxin administration. Similar metabolite changes were also reported in feline PD models, although the choline: creatine ratios were observed to decrease after MPTP administration. ${ }^{110}$

Huntington's disease. HD is primarily associated with a progressive atrophy and selective neuronal cell loss of the medium spiny neurons of the striatum. However, neuropathological analysis of postmortem HD brain demonstrates a reduction of $300-400 \mathrm{~g}$ in total brain weight compared with normal controls, and, as the striatum only weighs $\sim 20 \mathrm{~g}$, then clearly $\sim 90+\%$ of the atrophy is extrastriatal in HD and marked cortical loss is observed. 3-nitroproprionic acid (3-NP) is a mitochondrial inhibitor used to create an animal model for HD. Unlike intrastriatal kainic acid (KA) injections, which exhibit a nonselective necrosis, ${ }^{111} 3$-NP has been shown to selectively destroy medium-sized spiny GABAergic neurons with a relative sparing of interneurons and afferents, ${ }^{112,149}$ as is observed in the HD striatum. This, together with the striking morphological and behavioral similarities, supports the view that a deficit in energy metabolism may be involved in the etiology of HD. In primates subjected to 3-NP administration as two daily injections for 8-10 weeks, progressive decreases in NAA, creatine, and choline could be detected by in vivo
${ }^{1} \mathrm{H}-\mathrm{NMR}$ spectroscopy before the detection of elevated lactate levels. ${ }^{113}$ Changes in endogenous metabolite concentrations were demonstrable before the onset of striatal lesioning. Our own preliminary NMR spectroscopic studies have shown a global increase in succinate and decreased concentrations of NAA, $N$-acetylaspartylglutamate, and taurine, together with a decrease in GABA levels specific to the ventral and dorsal portions of the striatum (manuscript in preparation). Subsequent metabonomic studies have been performed to assess possible therapeutic strategies in toxin models of $\mathrm{HD}$, including drugs to correct brain energy deficits, ${ }^{39}$ striatal allografts, ${ }^{114}$ and neurotrophic factors. ${ }^{115}$

Xenobiotic studies. NMR spectroscopy has also been used to explore potential neurotoxic effects of xenobiotics. Although hydrazine, a metabolite of isoniazid and hydralazine, is most commonly associated with hepatic steatosis, it is also known to cause CNS effects such as seizures. ${ }^{1} \mathrm{H}$ MAS NMR investigation of brain tissues identified increased alanine, indicative of transaminase inhibition, and decreased hippocampal concentrations of aspartate, NAA, and myo-inositol. Integration of these results with NMR profiles of liver and kidney tissue achieved a more global perspective on hydrazine-induced toxicity. ${ }^{116}$

It is debatable as to whether the use of neurotoxic compounds can be regarded as truly neurodegenerative. However, all animal models are limited by their capacity to mimic only specific aspects of the neurodegenerative condition, in that they simulate certain aspects of pathogenic, histological, biochemical, or behavioral features, but may be of use in furthering the understanding of neurodegenerative mechanisms.

Genetic models of neurodegeneration. Transgenic animal models of several neurological diseases have been generated that are neuropathologically and clinically similar to the clinical disorders. For example, transgenic mice overexpressing human $\alpha$-synuclein, a major component in the formation of Lewy bodies observed in $\mathrm{PD}$, not only show $\alpha$-synuclein-positive cytoplasmic inclusions, but reveal loss of nigrostriatal dopaminergic terminals in the striatum and motor impairments. ${ }^{117} \mathrm{~A}$ transgenic model containing a doubly mutated form of the human $\alpha$-synuclein gene has been shown to exhibit age-related impairments in motor co-ordination and reductions in dopamine. ${ }^{118}$ Nuclear magnetic resonance spectroscopy has been applied to characterize the metabolic effects of genetic modification in several models. Brain extracts from mice transgenic for Sandhoff disease, a lysosomal storage disorder resulting from the accumulation of $\mathrm{N}$-acetyl-containing glycophospholipids in the brain, revealed the presence of $N$-acetylhexosamine-containing oligosaccharides that were not observed in matched control animals. ${ }^{119}$ Additional in vivo 
MRS studies identified signals from stored glycosphingolipids, which increased with disease progression.

Several transgenic mouse models exist for HD with the most common being the R6/1 and the R6/2 mouse models containing 115 and 150 CAG repeats, respectively. ${ }^{118}$ The R6/1 model is consistent with a less aggressive onset of HD than the R6/2 model. MRS studies report a $26 \%$ decrease of NAA in the corpus striatum of transgenic animals at 5 months of age. ${ }^{120}$ Nuclear magnetic resonance-based metabonomic studies in the R6/2 mouse model have identified the evolution of characteristic metabolite profiles across several biological matrices (urine, plasma, skeletal muscle, striatum, cerebral cortex, cerebellum, and brain stem). Clear differentiation of transgenic from wild-type mice was achieved in mice as young as 4 weeks old. ${ }^{76}$ The metabolic differences observed in the plasma and urine may yield useful biomarkers if they prove to be transferable to humans. The differentiation of choline species by highresolution NMR spectroscopy ${ }^{76}$ allowed the identification of glycerophosphocholine as the primary progressive neurochemical perturbation that was previously attributed to choline. ${ }^{121}$ More notably, choline levels were observed to decrease in most of the neuroanatomical regions analyzed in the R6/2 mouse. ${ }^{76}$ A recent study using GC in combination with time-of-flight MS analysis of serum reported changes in glycerol, mannitol, and several amino acids suggestive of a procatabolic phenotype in both the R6/2 mouse model and in a small number of HD patients that correlated with disease progression. ${ }^{122}$

The SCA3 mouse is a model for Machado-Joseph disease, a dominantly inherited spinocerebellar ataxia, also caused by expansions of CAG repeats. ${ }^{1} \mathrm{H}$ MAS NMR analysis of brain extracts from this model revealed a consistent increase in glutamine in both the cerebellum and cerebrum together with decreases in levels of GABA, choline, phosphocholine, and lactate. ${ }^{15}$

\section{MONITORING DISEASE PROGRESSION}

An important driver in current research into neuronal dysfunction is the identification of reliable biomarkers for disease progression and response to therapeutic intervention. To be truly useful, a biomarker must be quantifiable, reproducible, and analytically simple to measure. In addition, it is preferable that the biomarker is inexpensive to measure, has a limited variation in concentration or expression, and is unaffected by comorbid factors. Biomarkers that can indicate detection of neurodegenerative diseases in an early or even presymptomatic stage are essential. There is a paucity of suitable biomarkers for assessing disease progression in this group of disorders. Currently many potential diseasemodifying therapies are being developed and evaluated at the preclinical stage and will lead to clinical trials in the near future for which biomarkers are urgently needed. For the evaluation of therapies the biomarker needs to change linearly with disease progression and closely correlate with established clinicopathological parameters of the disease. ${ }^{123}$ Although there may be situations in which a single molecule or protein will fulfill this requirement, in practice most diseases are polygenic in origin, often with strong environmental influences, and consequently there will be a complex syndrome or fingerprint of molecular markers associated with disease state, and the efficacy or toxicity of drug that will evolve through time. Thus, in reality, combinations of biomarkers are far more likely than single entities to form the basis of a reliable diagnostic test. The capacity of metabonomics for generating a metabolic fingerprint is uniquely suited to identifying such combination biomarkers and can be placed alongside conventional clinical assessments encompassing specific cognitive and neurophysiological testing and supplemented with genomic and proteomic profiling. Many different approaches are being undertaken to identify biomarkers and include imaging and neurophysiological and cognitive testing in addition to newer technologies such as biochemical, proteomic, metabonomic, and gene array profiling of tissue and biofluids from patients. Since the metabonomic analysis of biofluids is a relatively noninvasive and rapid profiling tool, it is highly suitable for monitoring of disease progression that requires a multisampling protocol.

\section{Alzheimer's disease}

Alzheimer's disease is the most common form of dementia and is difficult to diagnose in the very early stages. However, in recent years, there has been interest in the clinical picture of "mild cognitive impairment" (MCI), which may represent a very early form of AD in some patients. ${ }^{124}$ Currently there is no clinical method to determine whether a patient with MCI has incipient $\mathrm{AD}$ or has a benign form of MCI without progression; the conversion rate from MCI to $\mathrm{AD}$ with dementia is about $15 \%$ per year. ${ }^{125}$ Thus there is a great need for diagnostic biomarkers to identify incipient $\mathrm{AD}$ in MCI cases so that early symptomatic (i.e., cholinsterase inhibitors) or disease-modifying treatments may be given early in the course of disease. MRS is used to measure relative amounts of metabolites in selected brain areas. Reduced $\mathrm{NAA} / \mathrm{Cr}$ ratios have been suggested as a marker of subsequent conversion from MCI to AD. ${ }^{126}$ Decreases in NAA levels in the temporal lobe have been reported to correlate closely with cognitive decline and to distinguish AD patients from a group exhibiting non-Alzheimer's dementia. ${ }^{127}$ Elevations in choline levels together with a decline in NAA concentrations associated with $\mathrm{AD}$ were also observed in senescence. ${ }^{41}$ 


\section{Parkinson's disease}

Parkinson's disease also can be very difficult to diagnose in its early stages and may be mimicked by other diseases such as essential tremor, multiple system atrophy, and progressive supranuclear palsy. In addition, by the time a patient presents with the clinical features of $\mathrm{PD}$, there is already a $\sim 50 \%$ reduction in dopaminergic nigral cells, ${ }^{128}$ and it appears that this preclinical phase of PD lasts for $\sim 5$ years. ${ }^{129}$ Clearly treatment with putative neuroprotective treatments is likely to be most beneficial in this preclinical phase before marked neuronal loss has occurred. Magnetic resonance spectroscopy is used to measure relative amounts of metabolites in selected brain areas. Reduced NAA/Cr levels have been suggested as a marker of cognitive decline in nondemented PD patients relative to controls. ${ }^{90}$

\section{Huntington's disease}

Although there is a clear genetic test for HD, clinical trials for HD remain challenging and, to date, only a few double-blind phase III trials have been conducted. There is an urgent need to obtain biomarkers of disease progression and response to therapeutic intervention. The current method of assessment for clinical disease progression is the Unified Huntington's Disease Rating Scale (UHDRS), which lacks sensitivity and specificity particularly over short periods of time. Therefore, the identification of biomarkers that could also be used to track disease progression would be invaluable. In addition, markers capable of detecting disease related changes in presymptomatic HD gene carriers will be essential for the future detection and monitoring of treatments that can delay disease onset. A GC-MS profiling study by Underwood and coworkers ${ }^{122}$ indicates that low-molecular-weight metabolites such as glycerol and amino acids may be useful in monitoring disease progression in HD patients.

\section{Multiple sclerosis}

Multiple sclerosis is characterized by the degeneration of the myelin sheath leading to neuronal damage and loss that ultimately results in the irreversibility of the debilitating disorder. Alterations in metabolite levels are described by NMR spectroscopy that are specific for axonal damage, demyelination, and inflammation and have been monitored during the remittingrelapsing phases typical of the disease. ${ }^{23,84,130}$ Numerous in vivo ${ }^{1} \mathrm{H}$ MRS studies in patients with multiple sclerosis have revealed reductions in NAA in both lesions and normal white matter. ${ }^{37,131-134}$ The recovery of NAA, which coincides with the improvement in disability, ${ }^{135}$ appears to be related to diminishing edema and remyelination. ${ }^{84,130}$

\section{DRUG DEVELOPMENT AND TOXICITY}

Nuclear magnetic resonance spectroscopy generates profiles for molecules of both endogenous and xenobiotic origin and has a long history in the investigation of drug metabolism. ${ }^{136,137}$ Both conventional and ${ }^{1} \mathrm{H}$ MAS NMR spectroscopic analyses have been used to characterize the toxicity profiles of toxins and candidate drugs and to generate information on putative metabolic pathways. Thus, NMR spectroscopy is a useful tool in drug development, which demands rapid resolution of safety issues with an emphasis on interspecies comparisons of mechanisms of toxicity to determine relevance to man. Furthermore, recent studies indicate that the predose metabolic profile can in some instances be used to predict the dominant metabolism of pharmaceutical compounds. ${ }^{138}$

\section{THE USE OF METABONOMICS IN DEVELOPMENT OF THERAPEUTICS}

Baseline metabolite profiles obtained from HD and PD patients have been acquired and characterized ${ }^{79}$ from which to determine the clinical benefit of intracerebral stem cell transplantation. ${ }^{139}$ In HD and PD patients receiving stem cell grafts, concentrations of NAA were not significantly different from controls. Furthermore, the reported replenishment of NAA concentrations in PD and HD patients may suggest the maturation of stem cells in vivo, since immature fetal transplant cells possess low concentrations of NAA; however, the infiltration of dendritic processes cannot be ruled out. In mice intoxicated with MPTP, the adoptive transfer of Copaxone immune cells prevented NAA depletion and revealed protective properties toward dopaminergic neurons in the substantia nigra pars compacta. ${ }^{108}$ In PD patients receiving thalamotomy to control parkinsonian tremor, further reductions in NAA/choline ratios were reported in the substantia nigra after stereotaxic surgery. ${ }^{140,141}$ Clinical improvements in motor function in the majority of patients after thalamotomy putatively arises from remote metabolic consequences beyond the lesion site.

In vivo and in vitro animal experiments and recent studies in humans have shown that oral creatine supplementation may delay the progression of HD..$^{90,142-146}$ Creatine has several potential neuroprotective effects, including buffering intracellular mitochondrial energy reserves, stabilizing intracellular calcium, and inhibiting activation of the mitochondrial permeability transition pore, which have all been linked to apoptotic and oxidative cell death. Initial pilot ${ }^{1} \mathrm{H}$ MRS studies have shown alterations in glutamate and glutamine ratios after creatine treatment that may be indicative of creatine enhancing the energy-dependent conversion of 
glutamate to glutamine, which has been shown to be perturbed in $\mathrm{HD}^{76,90,121}$

A recent study by Coen and coworkers ${ }^{19}$ showed that, on the basis of NMR spectroscopic analysis of human CSF, viral meningitis could be differentiated from meningitis of bacterial or fungal origin. A range of metabolites, of both mammalian and microbial origin, were responsible for disease classification. A longitudinal evaluation of a patient with cryptococcal meningitis further showed that the metabolic profiles correlated strongly with response to therapy.

\section{CONCLUSION}

The potential of metabonomics in improving the early diagnosis and detection of neurodegenerative diseases has been reviewed, with particular emphasis on the contribution of NMR spectroscopic strategies. Clearly, the hope and expectation around the application of this technology, to the study of human disease, is that novel biomarkers will be discovered, which allow a deeper understanding of the molecular basis of disease processes, a better diagnostic for disease progression, and an efficient means of monitoring response to therapeutic intervention. Individually the "omics" technologies can be a useful addition to the armory of investigative tools used to define and monitor neurodegeneration. Although each of these technologies has room for maturation, there can be no dispute as to their potential value. ${ }^{16}$ The integration of metabonomic data with results obtained from transcriptomic and proteomic studies will ultimately achieve a more global understanding of neurodegenerative mechanisms. Integration of "omics" data is a nontrivial task and, to date, few attempts have been made to systematically integrate multilevel data, although an elegant pioneer study in schizophrenia has shown good correlation in transcriptomic, proteomic, and metabonomic data in which evidence of oxidative stress and perturbed energy metabolism was generated by each technology. ${ }^{147}$

With the rapid developments in NMR hardware and computational analysis of spectra, metabonomic technology has the potential to impact strongly on the early diagnosis of the disease. Furthermore, the discovery of appropriate biomarkers will facilitate more effective management and care of patients with these neurodegenerative diseases.

Acknowledgments: We are grateful to High $\mathrm{Q}$ for financial support (T. Tsang) and also to Professor Gillian Bates (Department of Medical and Molecular Genetics, Kings College London) and Gerard A. McLoughlin for helpful discussion and provision of figures.

\section{REFERENCES}

1. Griffin JL, Sang E, Evens T, Davies K, Clarke K. Metabolic profiles of dystrophin and utrophin expression in mouse models of Duchenne muscular dystrophy. FEBS Lett 530:109-116, 2002.

2. Clish CB, Davidov E, Oresic M, Plasterer TN, Lavine G, Londo $\mathrm{T}$, et al. Integrative biological analysis of the APOE*3-leiden transgenic mouse. Omics 8:3-13, 2004.

3. Hwang D, Smith JJ, Leslie DM, Weston AD, Rust AG, Ramsey $\mathrm{S}$, et al. A data integration methodology for systems biology: experimental verification. Proc Natl Acad Sci USA 102:1730217307, 2005.

4. Miller RM, Federoff HJ. Microarrays in Parkinson's disease: a systematic approach. NeuroRx 3:318-325, 2006.

5. Olson NE. The microarray data analysis process: from raw to biological significance. NeuroRx 3:371-381, 2006.

6. Nicholson JK, Lindon JC, Holmes E. 'Metabonomics': understanding the metabolic responses of living systems to pathophysiological stimuli via multivariate statistical analysis of biological NMR spectroscopic data. Xenobiotica 29:1181-1189, 1999.

7. Nicholson JK, Connelly J, Lindon JC, Holmes E. Metabonomics: a platform for studying drug toxicity and gene function. Nat Rev Drug Discov 1:153-161, 2002.

8. Fiehn O. Metabolomics: the link between genotypes and phenotypes. Plant Mol Biol 48:155-171, 2002.

9. Yang J, Xu G, Zheng Y, Kong H, Pang T, Lv S, et al. Diagnosis of liver cancer using HPLC-based metabonomics avoiding falsepositive result from hepatitis and hepatocirrhosis diseases. J Chromatogr B Analyt Technol Biomed Life Sci 813:59-65, 2004.

10. Odunsi K, Wollman RM, Ambrosone CB, Hutson A, McCann SE, Tammela J, et al. Detection of epithelial ovarian cancer using 1H-NMR-based metabonomics. Int J Cancer 113:782-788, 2005.

11. Griffiths JR, Stubbs M. Opportunities for studying cancer by metabolomics: preliminary observations on tumors deficient in hypoxia-inducible factor 1. Adv Enzyme Regul 43:67-76, 2003.

12. Yang J, Xu G, Hong Q, Liebich HM, Lutz K, Schmulling RM, et al. Discrimination of Type 2 diabetic patients from healthy controls by using metabonomics method based on their serum fatty acid profiles. J Chromatogr B Analyt Technol Biomed Life Sci 813:53-58, 2004.

13. Brindle JT, Antti H, Holmes E, Tranter G, Nicholson JK, Bethell $\mathrm{HW}$, et al. Rapid and noninvasive diagnosis of the presence and severity of coronary heart disease using 1H-NMR-based metabonomics. Nat Med 8:1439-1444, 2002.

14. Sabatine MS, Liu E, Morrow DA, Heller E, McCarroll R, Wiegand $\mathrm{R}$, et al. Metabolomic identification of novel biomarkers of myocardial ischemia. Circulation 112:3868-3875, 2005.

15. Griffin JL, Cemal CK, Pook MA. Defining a metabolic phenotype in the brain of a transgenic mouse model of spinocerebellar ataxia 3. Physiol Genomics 16:334-340, 2004.

16. Dunckley T, Coon KD, Stephan DA. Discovery and development of biomarkers of neurological disease. Drug Discov Today 10: 326-334, 2005.

17. Prabakaran S, Swatton JE, Ryan MM, Huffaker SJ, Huang JT, Griffin JL, et al. Mitochondrial dysfunction in schizophrenia: evidence for compromised brain metabolism and oxidative stress. Mol Psychiatry 9:684-697, 2004.

18. Barshop BA. Metabolomic approaches to mitochondrial disease: correlation of urine organic acids. Mitochondrion 4:521-527, 2004.

19. Coen M, O’Sullivan M, Bubb WA, Kuchel PW, Sorrell T. Proton nuclear magnetic resonance-based metabonomics for rapid diagnosis of meningitis and ventriculitis. Clin Infect Dis 41:15821590, 2005.

20. Braun KP, Gooskens RH, Vandertop WP, Tulleken CA, van der Grond J. 1H magnetic resonance spectroscopy in human hydrocephalus. J Magn Reson Imaging 17:291-299, 2003.

21. Wang Y, Holmes E, Nicholson JK, Cloarec O, Chollet J, Tanner $\mathrm{M}$, et al. Metabonomic investigations in mice infected with Schistosoma mansoni: an approach for biomarker identification. Proc Natl Acad Sci USA 101:12676-12681, 2004. 
22. Rudkin TM, Arnold DL. Proton magnetic resonance spectroscopy for the diagnosis and management of cerebral disorders. Arch Neurol 56:919-926, 1999.

23. Kapeller P, McLean MA, Griffin CM, Chard D, Parker GJ, Barker GJ, et al. Preliminary evidence for neuronal damage in cortical grey matter and normal appearing white matter in short duration relapsing-remitting multiple sclerosis: a quantitative MR spectroscopic imaging study. J Neurol 248:131-138, 2001.

24. Karrenbauer VD, Leoni V, Lim ET, Giovannoni G, Ingle GT, Sastre-Garriga J, et al. Plasma cerebrosterol and magnetic resonance imaging measures in multiple sclerosis. Clin Neurol Neurosurg 108:456-460, 2006.

25. Tartaglia MC, Arnold DL. The role of MRS and fMRI in multiple sclerosis. Adv Neurol 98:185-202, 2006

26. Frisoni GB, Filippi M. Multiple sclerosis and Alzheimer's disease through the looking glass of MR imaging. AJNR Am J Neuroradiol 26:2488-2491, 2005.

27. Kleiner-Fisman G, Bergeron C, Lang AE. Presentation of Creutzfeldt-Jakob disease as acute corticobasal degeneration syndrome. Mov Disord 19:948-949, 2004.

28. Jenkins BG, Koroshetz WJ, Beal MF, Rosen BR. Evidence for impairment of energy metabolism in vivo in Huntington's disease using localized 1H NMR spectroscopy. Neurology 43: 2689-2695, 1993.

29. Brouwer OF, Laboyrie PM, Peters AC, Vielvoye GJ. Follow-up magnetic resonance imaging in Hallervorden-Spatz disease. Clin Neurol Neurosurg 94:S57-S60, 1992.

30. Kang PB, Hunter JV, Kaye EM. Lactic acid elevation in extramitochondrial childhood neurodegenerative diseases. $J$ Child Neurol 16:657-660, 2001.

31. Khiat A, Bard C, Lacroix A, Rousseau J, Boulanger Y. Brain metabolic alterations in Cushing's syndrome as monitored by proton magnetic resonance spectroscopy. NMR Biomed 12:357363, 1999

32. Khiat A, Yared Z, Bard C, Lacroix A, Boulanger Y. Long-term brain metabolic alterations in exogenous Cushing's syndrome as monitored by proton magnetic resonance spectroscopy. Brain Res 911:134-140, 2001.

33. Gallelli KA, Wagner CM, Karchemskiy A, Howe M, Spielman D, Reiss A, et al. $N$-acetylaspartate levels in bipolar offspring with and at high-risk for bipolar disorder. Bipolar Disord 7:589-597, 2005.

34. Choi IY, Lee SP, Guilfoyle DN, Helpern JA. In vivo NMR studies of neurodegenerative diseases in transgenic and rodent models. Neurochem Res 28:987-1001, 2003.

35. Li LM, Caramanos Z, Cendes F, Andermann F, Antel SB, Dubeau $F$, et al. Lateralization of temporal lobe epilepsy (TLE) and discrimination of TLE from extra-TLE using pattern analysis of magnetic resonance spectroscopic and volumetric data. Epilepsia 41:832-842, 2000.

36. Kalra S, Arnold DL, Cashman NR. Biological markers in the diagnosis and treatment of ALS. J Neurol Sci 165:S27-S32, 1999.

37. Matthews PM, Pioro E, Narayanan S, De Stefano N, Fu L, Francis G, et al. Assessment of lesion pathology in multiple sclerosis using quantitative MRI morphometry and magnetic resonance spectroscopy. Brain 119:715-722, 1996.

38. Seppi K, Schocke MF. An update on conventional and advanced magnetic resonance imaging techniques in the differential diagnosis of neurodegenerative parkinsonism. Curr Opin Neurol 18: 370-375, 2005.

39. Kasparova S, Sumbalova Z, Bystricky P, Kucharska J, Liptaj T, Mlynarik V, et al. Effect of coenzyme Q10 and vitamin E on brain energy metabolism in the animal model of Huntington's disease. Neurochem Int 48:93-99, 2006.

40. Fernandez A, Garcia-Segura JM, Ortiz T, Montoya J, Maestu F, Gil-Gregorio P, et al. Proton magnetic resonance spectroscopy and magnetoencephalographic estimation of delta dipole density: a combination of techniques that may contribute to the diagnosis of Alzheimer's disease. Dement Geriatr Cogn Disord 20:169177, 2005.

41. Pfefferbaum A, Adalsteinsson E, Spielman D, Sullivan EV, Lim KO. In vivo brain concentrations of $\mathrm{N}$-acetyl compounds, creat- ine, and choline in Alzheimer's disease. Arch Gen Psychiatry 56:185-192, 1999.

42. Preul MC, Caramanos Z, Collins DL, Villemure JG, Leblanc R, Olivier A, et al. Accurate, noninvasive diagnosis of human brain tumors by using proton magnetic resonance spectroscopy. Nat Med 2:323-325, 1996.

43. Brown FF, Campbell ID, Kuchel PW, Rabenstein DC. Human erythrocyte metabolism studies by $1 \mathrm{H}$ spin echo NMR. FEBS Lett 82:12-16, 1977.

44. Ohsaka A, Yoshikawa K, Matuhasi T. Detection by proton nuclear magnetic resonance of elevated lactate concentration in serums from patients with malignant tumors. Jpn J Med Sci Biol 32:305-309, 1979.

45. Bales JR, Higham DP, Howe I, Nicholson JK, Sadler PJ. Use of high-resolution proton nuclear magnetic resonance spectroscopy for rapid multi-component analysis of urine. Clin Chem 30:426432, 1984.

46. Nicholson JK, Buckingham MJ, Sadler PJ. High resolution $1 \mathrm{H}$ n.m.r. studies of vertebrate blood and plasma. Biochem J 211: 605-615, 1983

47. Nicholson JK, Timbrell JA, Sadler PJ. Proton NMR spectra of urine as indicators of renal damage: mercury-induced nephrotoxicity in rats. Mol Pharmacol 27:644-651, 1985.

48. Cheng LL, Newell K, Mallory AE, Hyman BT, Gonzalez RG. Quantification of neurons in Alzheimer and control brains with ex vivo high resolution magic angle spinning proton magnetic resonance spectroscopy and stereology. Magn Reson Imaging 20: 527-533, 2002.

49. Cheng LL, Chang IW, Louis DN, Gonzalez RG. Correlation of high-resolution magic angle spinning proton magnetic resonance spectroscopy with histopathology of intact human brain tumor specimens. Cancer Res 58:1825-1832, 1998.

50. Cheng LL, Ma MJ, Becerra L, Ptak T, Tracey I, Lackner A, et al. Quantitative neuropathology by high resolution magic angle spinning proton magnetic resonance spectroscopy. Proc Natl Acad Sci USA 94:6408-6413, 1997.

51. Barton SJ, Howe FA, Tomlins AM, Cudlip SA, Nicholson JK, Bell BA, et al. Comparison of in vivo 1H MRS of human brain tumours with 1H HR-MAS spectroscopy of intact biopsy samples in vitro. Magma 8:121-128, 1999.

52. Fu R, Brey WW, Shetty K, Gor'kov P, Saha S, Long JR, et al Ultra-wide bore $900 \mathrm{MHz}$ high-resolution NMR at the National High Magnetic Field Laboratory. J Magn Reson 177:1-8, 2005.

53. Sidelmann UG, Braumann U, Hoffmann M, Spraul M, Lindon JC, Nicholson JK, et al. Directly coupled $800 \mathrm{MHz}$ HPLC-NMR spectroscopy of urine and its applications to the identification of the major phase II metabolites of tolfenamic acid. Anal Chem 69:607-612, 1997.

54. Martin GE, Hadden CE, Russell DJ, Kaluzny BD, Guido JE, Duholke WK, et al. Identification of degradants of a complex alkaloid using NMR cryoprobe technology and ACD/structure elucidator. J Heterocyclic Chem 39:1241-1250, 2002.

55. Griffin JL, Lehtimaki KK, Valonen PK, Grohn OH, Kettunen MI, Yla-Herttuala S, et al. Assignment of (1)H nuclear magnetic resonance visible polyunsaturated fatty acids in BT4C gliomas undergoing ganciclovir-thymidine kinase gene therapy-induced programmed cell death. Cancer Res 63:3195-3201, 2003.

56. Hinse C, Richter C, Provenzani A, Stockigt J. In vivo monitoring of alkaloid metabolism in hybrid plant cell cultures by $2 \mathrm{D}$ cryoNMR without labeling. Bioorg Med Chem 11:3913-3919, 2003.

57. Beckwith-Hall BM, Nicholson JK, Nicholls AW, Foxall PJ, Lindon JC, Connor SC, et al. Nuclear magnetic resonance spectroscopic and principal components analysis investigations into biochemical effects of three model hepatotoxins. Chem Res Toxicol 11:260-272, 1998.

58. Nicholson JK, Foxall PJ, Spraul M, Farrant RD, Lindon JC. 750 $\mathrm{MHz} 1 \mathrm{H}$ and $1 \mathrm{H}-13 \mathrm{C}$ NMR spectroscopy of human blood plasma. Anal Chem 67:793-811, 1995.

59. Sathasivam K, Baxendale S, Mangiarini L, Bertaux F, Hetherington C, Kanazawa I, et al. Aberrant processing of the Fugu HD (FrHD) mRNA in mouse cells and in transgenic mice. Hum Mol Genet 6:2141-2149, 1997.

60. Van Zijl PCM, O'Neil Johnson M, Mori S, Hurd RE. Magic- 
angle-gradient double-quantum-filtered COSY. J Magn Reson 113A:265-270, 1995.

61. Shockcor JP, Unger SE, Wilson ID, Foxall PJ, Nicholson JK, Lindon JC. Combined HPLC, NMR spectroscopy, and ion-trap mass spectrometry with application to the detection and characterization of xenobiotic and endogenous metabolites in human urine. Anal Chem 68:4431-4435, 1996.

62. Lindon JC, Nicholson JK, Holmes E, Keun HC, Craig A, Pearce JT, et al. Summary recommendations for standardization and reporting of metabolic analyses. Nat Biotechnol 23:833-838, 2005.

63. Garrod S, Humpher E, Connor SC, Connelly JC, Spraul M, Nicholson JK, et al. High-resolution (1)H NMR and magic angle spinning NMR spectroscopic investigation of the biochemical effects of 2-bromoethanamine in intact renal and hepatic tissue. Magn Reson Med 45:781-790, 2001.

64. Moka D, Vorreuther R, Schicha H, Spraul M, Humpfer E, Lipinski $\mathrm{M}$, et al. Biochemical classification of kidney carcinoma biopsy samples using magic-angle-spinning $1 \mathrm{H}$ nuclear magnetic resonance spectroscopy. J Pharm Biomed Anal 17:125-132, 1998.

65. Tomlins AM, Foxall PJ, Lynch MJ, Parkinson J, Everett JR, Nicholson JK. High resolution 1H NMR spectroscopic studies on dynamic biochemical processes in incubated human seminal fluid samples. Biochim Biophys Acta 1379:367-380, 1998.

66. Tate AR, Foxall PJ, Holmes E, Moka D, Spraul M, Nicholson JK, et al. Distinction between normal and renal cell carcinoma kidney cortical biopsy samples using pattern recognition of (1) H magic angle spinning (MAS) NMR spectra. NMR Biomed 13:64-71, 2000.

67. Eriksson L, Antti H, Gottfries J, Holmes E, Johansson E, Lindgren $\mathrm{F}$, et al. Using chemometrics for navigating in the large data sets of genomics, proteomics, and metabonomics (gpm). Anal Bioanal Chem 380:419-429, 2004.

68. Trygg J, Wold S. O2-PLS, a two-block (X-Y) latent variable regression (LVR) method with an integral OSC filter. J Chemometrics 17:53-64, 2003.

69. Turmaine M, Raza A, Mahal A, Mangiarini L, Bates GP, Davies SW. Nonapoptotic neurodegeneration in a transgenic mouse model of Huntington's disease. Proc Natl Acad Sci USA 97: 8093-8097, 2000.

70. Huang Y, Lisboa PJ, El-Deredy W. Tumour grading from magnetic resonance spectroscopy: a comparison of feature extraction with variable selection. Stat Med 22(1):147-164, 2003.

71. Cloarec O, Dumas ME, Trygg J, Craig A, Barton RH, Lindon JC, et al. Evaluation of the orthogonal projection on latent structure model limitations caused by chemical shift variability and improved visualization of biomarker changes in $1 \mathrm{H}$ NMR spectroscopic metabonomic studies. Anal Chem 77:517-526, 2005.

72. Ma'ayan A, Gardiner K, Iyengar R. The cognitive phenotype of Down syndrome: insights from intracellular network analysis. NeuroRx 3:394-403, 2006.

73. Govindaraju V, Young K, Maudsley AA. Proton NMR chemical shifts and coupling constants for brain metabolites. NMR Biomed 13:129-153, 2000.

74. Pfeuffer J, Tkac I, Provencher SW, Gruetter R. Toward an in vivo neurochemical profile: quantification of 18 metabolites in shortecho-time (1)H NMR spectra of the rat brain. J Magn Reson 141:104-120, 1999.

75. Tsang TM, Griffin JL, Haselden J, Fish C, Holmes E. Metabolic characterization of distinct neuroanatomical regions in rats by magic angle spinning $1 \mathrm{H}$ nuclear magnetic resonance spectroscopy. Magn Reson Med 53:1018-1024, 2005.

76. Tsang TM, Woodman B, McLoughlin GA, Griffin JL, Tabrizi SJ, Bates GP, et al. Metabolic characterization of the R6/2 transgenic mouse model of Huntington's disease by high-resolution MAS 1H NMR spectroscopy. J Proteome Res 5:483-492, 2006.

77. Griffin JL, Bollard M, Nicholson JK, Bhakoo K. Spectral profiles of cultured neuronal and glial cells derived from HRMAS (1)H NMR spectroscopy. NMR Biomed 15:375-384, 2002.

78. Urenjak J, Williams SR, Gadian DG, Noble M. Specific expression of $N$-acetylaspartate in neurons, oligodendrocyte-type-2 as- trocyte progenitors, and immature oligodendrocytes in vitro. J Neurochem 59:55-61, 1992.

79. Hoang TQ, Bluml S, Dubowitz DJ, Moats R, Kopyov O, Jacques $\mathrm{D}$, et al. Quantitative proton-decoupled 31P MRS and 1H MRS in the evaluation of Huntington's and Parkinson's diseases. Neurology 50:1033-1040, 1998.

80. Jenkins BG, Brouillet E, Chen YC, Storey E, Schulz JB, Kirschner $\mathrm{P}$, et al. Non-invasive neurochemical analysis of focal excitotoxic lesions in models of neurodegenerative illness using spectroscopic imaging. J Cereb Blood Flow Metab 16:450-461, 1996.

81. Jenkins BG, Rosas HD, Chen YC, Makabe T, Myers R, MacDonald M, et al. 1H NMR spectroscopy studies of Huntington's disease: correlations with CAG repeat numbers. Neurology 50: 1357-1365, 1998.

82. Horska A, Naidu S, Herskovits EH, Wang PY, Kaufmann WE, Barker PB. Quantitative 1H MR spectroscopic imaging in early Rett syndrome. Neurology 54:715-722, 2000.

83. Lucetti C, Del Dotto P, Gambaccini G, Bernardini S, Bianchi MC, Tosetti M, et al. Proton magnetic resonance spectroscopy (1H-MRS) of motor cortex and basal ganglia in de novo Parkinson's disease patients. Neurol Sci 22:69-70, 2001.

84. Tourbah A, Stievenart JL, Gout O, Fontaine B, Liblau R, Lubetzki $\mathrm{C}$, et al. Localized proton magnetic resonance spectroscopy in relapsing remitting versus secondary progressive multiple sclerosis. Neurology 53:1091-1097, 1999.

85. Pears MR, Cooper JD, Mitchison HM, Mortishire-Smith RJ, Pearce DA, Griffin JL. High resolution 1H NMR-based metabolomics indicates a neurotransmitter cycling deficit in cerebral tissue from a mouse model of Batten disease. J Biol Chem 280: 42508-42514, 2005.

86. Viant MR, Lyeth BG, Miller MG, Berman RF. An NMR metabolomic investigation of early metabolic disturbances following traumatic brain injury in a mammalian model. NMR Biomed 18:507-516, 2005.

87. Tanner CM, Ottman R, Goldman SM, Ellenberg J, Chan P, Mayeux R, et al. Parkinson's disease in twins: an etiologic study. Jama 281:341-346, 1999.

88. Weeks RA, Piccini P, Harding AE, Brooks DJ. Striatal D1 and D2 dopamine receptor loss in asymptomatic mutation carriers of Huntington's disease. Ann Neurol 40:49-54, 1996.

89. Sveinbjornsdottir S, Hicks AA, Jonsson T, Petursson H, Gugmundsson G, Frigge ML, et al. Familial aggregation of Parkinson's disease in Iceland. N Engl J Med 343:1765-1770, 2000.

90. Bender A, Auer DP, Merl T, Reilmann R, Saemann P, Yassouridis A, et al. Creatine supplementation lowers brain glutamate levels in Huntington's disease. J Neurol 252:36-41, 2005.

91. Kitada T, Asakawa S, Hattori N, Matsumine H, Yamamura Y, Minoshima S, et al. Mutations in the parkin gene cause autosomal recessive juvenile parkinsonism. Nature 392:605-608, 1998.

92. Kruger R, Kuhn W, Muller T, Woitalla D, Graeber M, Kosel S, et al. Ala30Pro mutation in the gene encoding $\alpha$-synuclein in Parkinson's disease. Nat Genet 18:106-108, 1998.

93. Brouillet E, Hantraye P, Ferrante RJ, Dolan R, Leroy-Willig A, Kowall NW, et al. Chronic mitochondrial energy impairment produces selective striatal degeneration and abnormal choreiform movements in primates. Proc Natl Acad Sci USA 92:7105-7109, 1995.

94. Polymeropoulos MH, Lavedan C, Leroy E, Ide SE, Dehejia A, Dutra A, et al. Mutation in the $\alpha$-synuclein gene identified in families with Parkinson's disease. Science 276:2045-2047, 1997.

95. Bonifati V, Rizzu P, van Baren MJ, Schaap O, Breedveld GJ, Krieger E, et al. Mutations in the DJ-1 gene associated with autosomal recessive early-onset parkinsonism. Science 299:256259, 2003.

96. Paisan-Ruiz C, Jain S, Evans EW, Gilks WP, Simon J, van der Brug M, et al. Cloning of the gene containing mutations that cause PARK8-linked Parkinson's disease. Neuron 44:595-600, 2004.

97. Valente EM, Abou-Sleiman PM, Caputo V, Muqit MM, Harvey K, Gispert S, et al. Hereditary early-onset Parkinson's disease caused by mutations in PINK1. Science 304:1158-1160, 2004.

98. Klawans HL, Stein RW, Tanner CM, Goetz CG. A pure parkin- 
sonian syndrome following acute carbon monoxide intoxication. Arch Neurol 39:302-304, 1982.

99. Huang CC, Lu CS, Chu NS, Hochberg F, Lilienfeld D, Olanow W, et al. Progression after chronic manganese exposure. Neurology 43:1479-1483, 1993.

100. Helmuth L. Neuroscience. Pesticide causes Parkinson's in rats. Science 290:1068, 2000.

101. Langston JW, Forno LS, Rebert CS, Irwin I. Selective nigral toxicity after systemic administration of 1-methyl-4-phenyl1,2,5,6-tetrahydropyrine (MPTP) in the squirrel monkey. Brain Res 292:390-394, 1984.

102. Carlsson A, Lindqvist M, Magnusson T. 3,4-Dihydroxyphenylalanine and 5-hydroxytryptophan as reserpine antagonists. $\mathrm{Na}$ ture 180:1200, 1957.

103. Ungerstedt U. 6-Hydroxy-dopamine induced degeneration of central monoamine neurons. Eur J Pharmacol 5:107-110, 1968

104. Hastings TG, Lewis DA, Zigmond MJ. Role of oxidation in the neurotoxic effects of intrastriatal dopamine injections. Proc Natl Acad Sci USA 93:1956-1961, 1996.

105. Bloem BR, Irwin I, Buruma OJ, Haan J, Roos RA, Tetrud JW, et al. The MPTP model: versatile contributions to the treatment of idiopathic Parkinson's disease. J Neurol Sci 97:273-293, 1990

106. Chen YC, Galpern WR, Brownell AL, Matthews RT, Bogdanov $\mathrm{M}$, Isacson O, et al. Detection of dopaminergic neurotransmitter activity using pharmacologic MRI: correlation with PET, microdialysis, and behavioral data. Magn Reson Med 38:389-398, 1997.

107. Smith DA, Clarke LP, Fiedler JA, Murtagh FR, Bonaroti EA, Sengstock GJ, et al. Use of a clinical MR scanner for imaging the rat brain. Brain Res Bull 31:115-120, 1993

108. Boska MD, Lewis TB, Destache CJ, Benner EJ, Nelson JA, Uberti $\mathrm{M}$, et al. Quantitative $1 \mathrm{H}$ magnetic resonance spectroscopic imaging determines therapeutic immunization efficacy in an animal model of Parkinson's disease. J Neurosci 25:16911700,2005

109. Brownell AL, Jenkins BG, Elmaleh DR, Deacon TW, Spealman $\mathrm{RD}$, Isacson O. Combined PET/MRS brain studies show dynamic and long-term physiological changes in a primate model of Parkinson's disease. Nat Med 4:1308-1312, 1998.

110. Podell M, Hadjiconstantinou M, Smith MA, Neff NH. Proton magnetic resonance imaging and spectroscopy identify metabolic changes in the striatum in the MPTP feline model of parkinsonism. Exp Neurol 179:159-166, 2003.

111. Sperk G. Kainic acid seizures in the rat. Prog Neurobiol 42:1-32, 1994.

112. Brouillet E, Conde F, Beal MF, Hantraye P. Replicating Huntington's disease phenotype in experimental animals. Prog $\mathrm{Neu}$ robiol 59:427-468, 1999.

113. Dautry C, Conde F, Brouillet E, Mittoux V, Beal MF, Bloch G, et al. Serial 1H-NMR spectroscopy study of metabolic impairment in primates chronically treated with the succinate dehydrogenase inhibitor 3-nitropropionic acid. Neurobiol Dis 6:259-268, 1999.

114. Palfi S, Conde F, Riche D, Brouillet E, Dautry C, Mittoux V, et al. Fetal striatal allografts reverse cognitive deficits in a primate model of Huntington's disease. Nat Med 4:963-966, 1998.

115. Mittoux V, Joseph JM, Conde F, Palfi S, Dautry C, Poyot T, et al. Restoration of cognitive and motor functions by ciliary neurotrophic factor in a primate model of Huntington's disease. Hum Gene Ther 11:1177-1187, 2000.

116. Garrod S, Bollard ME, Nicholls AW, Connor SC, Connelly J, Nicholson JK, et al. Integrated metabonomic analysis of the multiorgan effects of hydrazine toxicity in the rat. Chem Res Toxicol 18:115-122, 2005.

117. Masliah E, Rockenstein E, Veinbergs I, Mallory M, Hashimoto M, Takeda A, et al. Dopaminergic loss and inclusion body formation in $\alpha$-synuclein mice: implications for neurodegenerative disorders. Science 287:1265-1269, 2000.

118. Richfield EK, O'Brien CF, Eskin T, Shoulson I. Heterogeneous dopamine receptor changes in early and late Huntington's disease. Neurosci Lett 132:121-126, 1991.

119. Holowenko D, Peeling J, Sutherland G. 1H NMR properties of $\mathrm{N}$-acetylaspartylglutamate in extracts of nervous tissue of the rat. NMR Biomed 5:43-47, 1992.
120. van Dellen A, Welch J, Dixon RM, Cordery P, York D, Styles P, et al. $N$-acetylaspartate and DARPP-32 levels decrease in the corpus striatum of Huntington's disease mice. NeuroReport 11: 3751-3757, 2000.

121. Jenkins BG, Klivenyi P, Kustermann E, Andreassen OA, Ferrante RJ, Rosen BR, et al. Nonlinear decrease over time in $N$-acetyl aspartate levels in the absence of neuronal loss and increases in glutamine and glucose in transgenic Huntington's disease mice. J Neurochem 74:2108-2119, 2000.

122. Underwood BR, Broadhurst D, Dunn WB, Ellis DI, Michell AW, Vacher C, et al. Huntington's disease patients and transgenic mice have similar pro-catabolic serum metabolite profiles. Brain 129: 877-886, 2006.

123. Henley SM, Bates GP, Tabrizi SJ. Biomarkers for neurodegenerative diseases. Curr Opin Neurol 18:698-705, 2005.

124. Winblad B, Palmer K, Kivipelto M, Jelic V, Fratiglioni L, Wahlund LO, et al. Mild cognitive impairment-beyond controversies, towards a consensus: report of the International Working Group on Mild Cognitive Impairment. J Intern Med 256:240-246, 2004.

125. DeCarli C. Mild cognitive impairment: prevalence, prognosis, aetiology, and treatment. Lancet Neurol 2:15-21, 2003.

126. Metastasio A, Rinaldi P, Tarducci R, Mariani E, Feliziani FT, Cherubini A, et al. Conversion of MCI to dementia: role of proton magnetic resonance spectroscopy. Neurobiol Aging 27:926-932, 2006.

127. Frederick BD, Lyoo IK, Satlin A, Ahn KH, Kim MJ, YurgelunTodd DA, et al. In vivo proton magnetic resonance spectroscopy of the temporal lobe in Alzheimer's disease. Prog Neuropsychopharmacol Biol Psychiatry 28:1313-1322, 2004.

128. Spillantini MG, Schmidt ML, Lee VM, Trojanowski JQ, Jakes R, Goedert M. $\alpha$-synuclein in Lewy bodies. Nature 388:839-840, 1997.

129. Schlossmacher MG, Frosch MP, Gai WP, Medina M, Sharma N, Forno L, et al. Parkin localizes to the Lewy bodies of Parkinson's disease and dementia with Lewy bodies. Am J Pathol 160:16551667, 2002.

130. Mader I, Roser W, Kappos L, Hagberg G, Seelig J, Radue EW, et al. Serial proton MR spectroscopy of contrast-enhancing multiple sclerosis plaques: absolute metabolic values over 2 years during a clinical pharmacological study. AJNR Am J Neuroradiol 21: 1220-1227, 2000.

131. Arnold DL, Matthews PM, Francis G, Antel J. Proton magnetic resonance spectroscopy of human brain in vivo in the evaluation of multiple sclerosis: assessment of the load of disease. Magn Reson Med 14:154-159, 1990.

132. Davie CA, Barker GJ, Thompson AJ, Tofts PS, McDonald WI, Miller DH. 1H magnetic resonance spectroscopy of chronic cerebral white matter lesions and normal appearing white matter in multiple sclerosis. J Neurol Neurosurg Psychiatry 63:736-742, 1997.

133. Fu L, Matthews PM, De Stefano N, Worsley KJ, Narayanan S, Francis GS, et al. Imaging axonal damage of normal-appearing white matter in multiple sclerosis. Brain 121:103-113, 1998.

134. Narayana PA, Doyle TJ, Lai D, Wolinsky JS. Serial proton magnetic resonance spectroscopic imaging, contrast-enhanced magnetic resonance imaging, and quantitative lesion volumetry in multiple sclerosis. Ann Neurol 43:56-71, 1998.

135. Arnold DL, Riess GT, Matthews PM, Francis GS, Collins DL, Wolfson C, et al. Use of proton magnetic resonance spectroscopy for monitoring disease progression in multiple sclerosis. Ann Neurol 36:76-82, 1994.

136. Lindon JC, Holmes E, Nicholson JK. Pattern recognition methods and applications in biomedical magnetic resonance. Prog NMR Spectrosc 39:1-40, 2001.

137. Nicholson JK, Higham DP, Timbrell JA, Sadler PJ. Quantitative high resolution $1 \mathrm{H}$ NMR urinalysis studies on the biochemical effects of cadmium in the rat. Mol Pharmacol 36:398-404, 1989.

138. Clayton TA, Lindon JC, Cloarec O, Antti H, Charuel C, Hanton $\mathrm{G}$, et al. Pharmaco-metabonomic phenotyping and personalized drug treatment. Nature 440:1073-1077, 2006.

139. Ross BD, Hoang TQ, Bluml S, Dubowitz D, Kopyov OV, Jacques DB, et al. In vivo magnetic resonance spectroscopy of human fetal neural transplants. NMR Biomed 12:221-236, 1999.

140. Baik HM, Choe BY, Lee HK, Suh TS, Son BC, Lee JM. Metabolic alterations in Parkinson's disease after thalamotomy, as revealed by (1)H MR spectroscopy. Korean J Radiol 3:180-188, 2002. 
141. Baik HM, Choe BY, Son BC, Jeun SS, Kim MC, Lee KS, et al. Proton MR spectroscopic changes in Parkinson's diseases after thalamotomy. Eur J Radiol 47:179-187, 2003.

142. Verbessem P, Lemiere J, Eijnde BO, Swinnen S, Vanhees L, van Leemputte M, et al. Creatine supplementation in Huntington's disease: a placebo-controlled pilot trial. Neurology 61:925-930, 2003.

143. Hersch SM, Gevorkian S, Marder K, Moskowitz C, Feigin A, Cox M, et al. Creatine in Huntington's disease is safe, tolerable, bioavailable in brain and reduces serum $8 \mathrm{OH} 2^{\prime} \mathrm{dG}$. Neurology 66:250-252, 2006.

144. Tsang TM, Woodman B, McLoughlin G, Griffin JL, Tabrizi SJ, Bates GP, et al. Metabolic characterisation of the R6/2 transgenic mouse model of Huntington's disease by high-resolution MAS 1H NMR spectroscopy. J Proteome Res 5:483-492, 2006.

145. Matthews RT, Yang L, Jenkins BG, Ferrante RJ, Rosen BR, Kaddurah-Daouk R, et al. Neuroprotective effects of creatine and cyclocreatine in animal models of Huntington's disease. $\mathrm{J} \mathrm{Neu-}$ rosci 18:156-163, 1998.

146. Tabrizi SJ, Blamire AM, Manners DN, Rajagopalan B, Styles P,
Schapira AH, et al. Creatine therapy for Huntington's disease: clinical and MRS findings in a 1-year pilot study. Neurology 61:141-142, 2003.

147. Tsang TM, Huang JTJ, Holmes E, Bahn S. Metabolic profiling of plasma from discordant schizophrenia twins: correlation between lipid signals and global functioning in female schizophrenia patients. J Proteome Res 5:756-760, 2006.

148. Tkac I, Rao R, Georgieff MK, Gruetter R. Developmental and regional changes in the neurochemical profile of the rat brain determined by in vivo $1 \mathrm{H}$ NMR spectroscopy. Magn Reson Med 50:24-32, 2003.

149. Dautry C, Vaufrey F, Brouillet E, Bizat N, Henry PG, Conde F, et al. Early $N$-acetylaspartate depletion is a marker of neuronal dysfunction in rats and primates chronically treated with the mitochondrial toxin 3-nitropropionic acid. J Cereb Blood Flow Metab 20:789-799, 2000.

150. Matthews RT, Ferrante RJ, Klivenyi P, Yang L, Klein AM, Mueller G, et al. Creatine and cyclocreatine attenuate MPTP neurotoxicity. Exp Neurol 157:142-149, 1999. 